\title{
A SPATIAL DISTRIBUTIONMAP OF THE WILDFIRE RISK IN MONGOLIA USING DECISION SUPPORT SYSTEM
}

\author{
Elbegjargal Nasanbat ${ }^{\mathrm{a}, \mathrm{b}}$, Ochirkhuyag Lkhamjav ${ }^{\mathrm{b}}$, Amonjol Balkhai ${ }^{\mathrm{b}, \mathrm{c}}$, \\ Chuluunbaatar Tsevee-Oirov ${ }^{\mathrm{d}}$, Amarzaya Purev ${ }^{\mathrm{b}, \mathrm{e}}$ and Munkhzul Dorjsuren ${ }^{\mathrm{c}}$
}

\author{
$a^{*}$ National Remote Sensing Center, Juulchiny street-5, Ulaanbaatar 15160, Mongolia - n.elbegjargal@ gmail.com \\ b Mongolian Geospatial Association, P.O. Box 24/38, Post office-38, Ulaanbaatar 15141, Mongolia - mongeoinfo@ gmail.com, \\ ochirkhuyag@geomedeelel.mn \\ c Information and Research Institute of Meteorology Hydrology and Environment, Juulchiny street-5, \\ Ulaanbaatar 15160, Mongolia - b.amanjol@yahoo.com,nominzulaad@gmail.com \\ d The Ministry of Environment and Tourism, Government building II, United Nations Street-5/2, Chingeltei District, Ulaanbaatar \\ 15160, Mongolia - chuluunbaatar_ts@yahoo.com \\ ${ }^{\text {e }}$ Disaster Research Institute under national Emergency Agency, Partizani street-6, \\ Ulaanbaatar 210644, Mongolia - amarzaya_67@yahoo.com
}

KEY WORDS: MODIS, burnt area, fire hotspot, land cover, Multi-Criteria Evaluation Analysis, SPI

\begin{abstract}
:
Wildfire is a cause of major disturbance to ecosystems and economies throughout the world. Hence, the wildfire is a vital issue of environment for creating natural disaster and socio-economic damage to affect in ecosystem and human lives. Moreover, the forest and steppe fire are one of natural risks in issues of Mongolian economy. This paper attempted to identify a spatial distribution of both risk and damage cost of the wildfire in Mongolia. The variables are to affect in the forest and steppe fire such as a biophysical parameters, field and statistical yearbook were integrated by climatic data to apply all into GIS application. These analyses are applied to the approach of decision-making support system, particularly as a Multi-Criteria Evaluation Analysis (MCEA). In addition, an evaluation of data could be divided into three group factors namely; environmental, social economic and fire damage including seventeen input parameters. These factors are based on important criteria and rank of the wildfire risk levels. All initial parameters were integrated into spatial model and used to estimate the wildfire risk index. This index was divided into five categories: very high, high, moderate, low and non-risk. Results show that a percentage of the study area was predicted by wildfire risk index in each category as follows. About $6-8 \%$ of the study area identified as categories of the moderate and low risk; but 5-16\% of it was estimated as very high and high risk. In remaining category, $65 \%$ of the study area was occupied as a maximum value in the non-risk. Moreover, these results demonstrated that a spatial distribution map of wildfire risk was predicted well including five categories for the study period. The integration of these factors in GIS could be useful to identify risk area and to make the strategy and prevention of wildfire hazard for the stakeholder, government and local of decision makers. Furthermore, it could be helped to improve the management of the forest, ecological and biodiversity conservation.
\end{abstract}

\section{INTRODUCTION}

Wildfire is a main natural disaster and greatly influences to the ecosystems and economies in Mongolia. Hence, the wildfire is an important issue for creating natural disaster and socio-economic damage to the ecosystem and human lives. Several researchers were mainly described to that are according to their issues (Yao et al., 2016, Dong et al., 2005). Fires usually occur in dry ecosystems, typically in steppe and grassland area, when are uncontrolled wildfires outbreak due to the physical or natural events and human actions. Also, researchers found that the wildfire becomes a threat to the biodiversity and human habitat and contributes to mortality reasons of them (Ochirkhuyag et al., 2008). Moreover, the frequency of natural disasters and their impacts have increased whole world in recent years including Mongolia. As a result of global warming has been changed the disturbance to ecological balance.

In contrast, the wildfire in Mongolia, especially the northern and eastern part of area has been frequented the wildfire occurrence in every dry season (spring and fall) of the last years and was caused by increasing accumulation of the fire impact to the environment and natural resources. Therefore, according to the scholarly surveys, about $56 \%$ of the study area is located in a zone exposed to forest and grassland fires. About $98.5 \%$ of a considerable fraction of it covered with forests in a zone assessed as a high fire risk. In addition, Erdenetuya (2012) highlighted that about $95 \%$ of steppe and forest fires in Mongolia are caused by human activities. Wildfires constitute a major hazard that determine the spatial and temporal dynamics of forest ecosystems between 1981 and 1999, approximately 160 fires per year were recorded in Mongolia, such as each burnt area is an average of 2,933,659 ha (Goldammer, 1999). In Mongolia, fire is a major factor which determines the spatio-temporal dynamics of forest ecosystems (Chuluunbaatar, 1998). Another point of economic aspect is illustrated by the wildfire might lead to disastrous consequences such as huge economic and ecological losses in the forest coverage of Mongolia (Ochirsukh, 2011). In recently, total 5600 hectares of the forest area were burnt the ecological loss which has been estimated by 30.6 million MNT. Total 1052918 hectares of the steppe area were burnt the ecological loss that appraised by 4 billion MNT, whereas the economic loss was estimated by 137.3 million MNT (Badamsuren et al., 2016).

The risk map of fire is calculated by potential area, which is certainly affected the wildfire. According to the Huyen and Tuan (2008) method, the raw data of geospatial technology approaches that are mapped by fire risk map and integrated with socioeconomic and environmental information. It underlines that the remote sensing and Geographic Information System (GIS) techniques support for the detection of active fires, estimation of burnt area and damage of geo-statistical analysis. In general, researchers are currently applied to use the approach of decision support which is the estimation of fire risk. It is used by hazard map and damage assessment on grassland and forest area and analyzed the various methods including the logistic regression, methods of weighted overlaying and decision support method. In addition, this decision support method includes the MultiCriteria Evaluation Analysis (MCEA), analytic hierarchy process (AHP), fuzzy analysis, neural networks and classification tree etc. (Garavand and Yaralli, 2015; Chhetri et al., 2015; Cho et al., 
2017; Elbegjargal and Ochirkhuyag, 2016). In this study, we were used to apply the method of MCEA for the wildfire risk map of Mongolia.

An advantage of our study was taken the complex aspect of the forest and steppe fire which is considered to the damage cost and risk distribution. The main goal of the study is to map a spatial distribution of both risk and damage cost of the forest and steppe fire in Mongolia.

Moreover, the purpose of an evaluation the result was divided into three group factors, namely social economic, environmental and climate, and wildfire damage including the seventeen input parameters (Table 2). These factors are contributed to the outbreak of the local and regional wildfire which is linked to the variables of biophysical parameters of field and statistical yearbook were integrated by climatic data to apply all into GIS application. These analyses are applied to use the approach of decision-making support system as well as a MCEA.

\section{STUDY AREA}

The study area covers with forest and steppe area of Mongolia and locates the central part of Asia latitude between $41^{\circ}$ and $52^{\circ}$ $\mathrm{N}$ and longitude between $87^{\circ}$ and $120^{\circ} \mathrm{E}$. A total territory of Mongolia is $1,564,116 \mathrm{~km}^{2}$. About $7 \%$ of the total area covers with forest and $73 \%$ of it dominates by grassland (CIA, 2017). The northern part of area is covered by forested mountains and middle part is a huge grazing land which is steppe area, whereas the southern part covered by the Gobi and desert zone with lower elevation and drier climate (Batima et al., 2000). Moreover, Mongolia has a continental climate and it is characterized by hot summer and cold winter. A maximum temperature in summer reaches up to $41^{\circ} \mathrm{C}$, whereas a minimum temperature in winter ranges up $-53^{\circ} \mathrm{C}$ (Zhang et al., 2002).

The amount of annual precipitation is relatively low and it ranges $150-250 \mathrm{~mm}$ in the steppe regions, more than $400 \mathrm{~mm}$ in the mountain areas. Therefore, several researchers were described that $85-90 \%$ of the annual precipitation would have happened in the summer season (Dorjsuren et al., 2016).

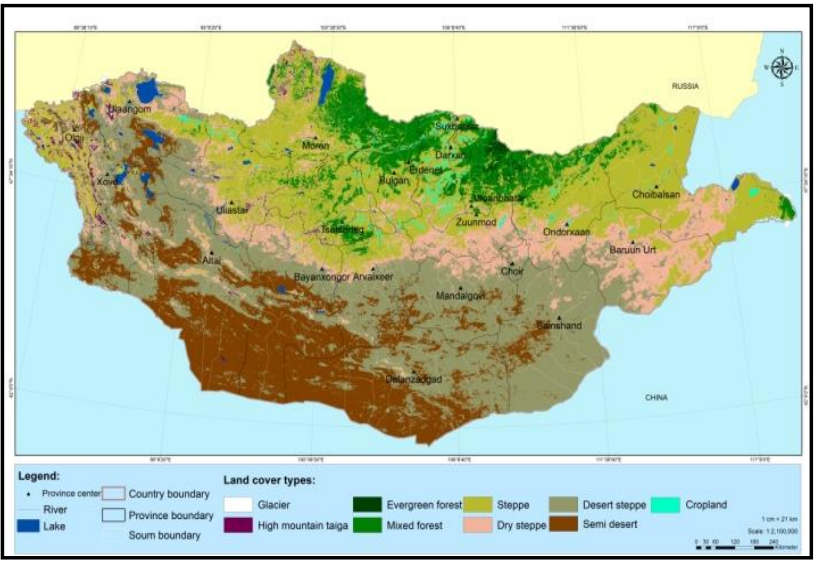

Figure 1. Land cover map of the study area (Khudulmur et al., 2014)

Serjmyadag et al., (2010) revealed by analyzing the occurrence of the steppe and forest fires have been considerably increased in the dry season of spring (end of March to June) and fall (September to November). Also, this result showed that a high risk of wildfire in Mongolia was occurred in the forest area, while $55.3 \%$ of area occupied in same region.

\section{METHOD AND MATERIALS}

\subsection{Method}

In this study, we were used that the Multi-Criteria Evaluation Analysis (MCEA) is proposed by Alejandro (2003) for decision making. For the image processing, the software of ArcMap was produced the map of wildfire. All data pre-processing and analysis of this study were used by software of ERDAS, IDRISI and ArcMap. In order to identify the wildfire, the spatial distribution of the high risk or optimal location in particular area was included the several parameters can be separately divided into three main groups of factors. These factors of three main groups include social economic, environmental and climate, and wildfire damage and are based on method of Malczewski (1999). Figure 2 presents a workflow of pre-processing and criteria selection to draw the mapping and statistical analysis for this study.

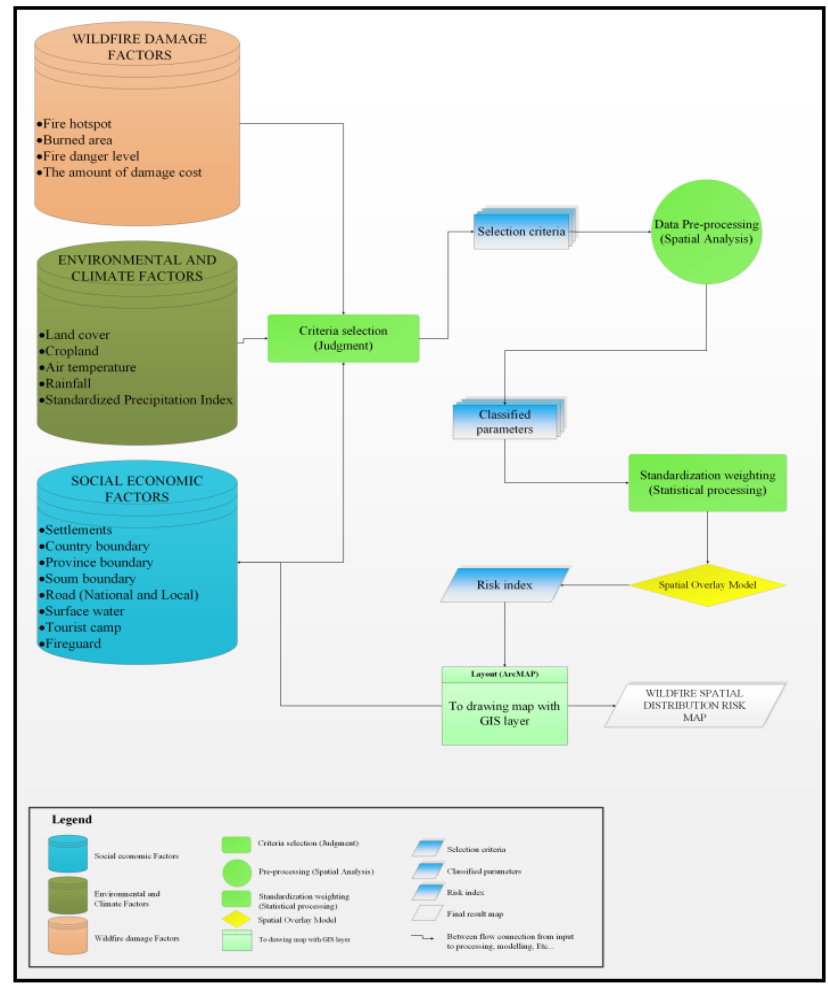

Figure 2. Flowchart of spatial distribution map of the wildfire for this study

In workflow processing method, parameter selection was based to utilize on expert judgment that includes the experts of forest, ecological, remote sensing and botanic etc. However, after data processing filter, the six parameters (Table 1) were created from the seventeen parameters. In addition, the spatial analysis method was used the pre-processing data analysis, whereas the statistical analysis performed the rank and weighted overlay.

One of three main groups are the environmental and climate factors that are to define the weather condition. Hence, we used to calculate the Standardized Precipitation Index (SPI; Svoboda et al., 2012) and evaluate dryness. This SPI is based on precipitation data of meteorological station for the study period that includes from May to October of 2000-2017. SPI is calculated by following Equation (1). 


$$
S P I=\frac{P-\bar{P}}{\sigma}
$$

where, $P$ is the amount of monthly precipitation.

$\bar{P}$ is the multi-year average of the amount of monthly precipitation.

$\sigma$ is the standard deviation of the amount of monthly precipitation.

The calculation of rank and weighted overlay of the wildfire criteria is computed by following Equation (2)

$$
w_{i}=\frac{\left(\mathrm{n}-r_{k}+1\right)}{\sum_{k=1}^{n}\left(\mathrm{n}-r_{k}+1\right)}
$$

where, $\quad w_{i}$ is the normalized weight for the criterion.

$n$ is the number of criteria under consideration $(\mathrm{k}=1$, $2 \ldots \mathrm{n})$.

$k$ is equal to 1 .

$r_{k}$ is rank of the dimension.

The estimation of the Multi-Criteria Evaluation Analysis (MCEA) is used to calculate by normalized weight using Equation (2), as given in Equation (3)

$$
S=\sum w_{i} x_{i}
$$

where, $S$ is the Multi-Criteria Evaluation Analysis (MCEA). $w_{i}$ is the weight of factor $i$,

$x_{i}$ is the score of class of factor $i$.

In order to compare between wildfire occurrence and SPI, the correlation coefficient $(r)$ is calculated the following Equation (4):

$$
r_{x y}=\sum_{i=1}^{n}\left[\left(x_{i}-\bar{x}\right)\left(y_{i}-\bar{y}\right)\right] / \sqrt{\sum_{i=1}^{n}\left[\left(x_{i}-\bar{x}\right)^{2}\left(y_{i}-\bar{y}\right)^{2}\right]}
$$

where, $\quad r_{x y}$ is the correlation coefficient.

$x_{i}$ and $y_{i}$ are the variables of wildfire occurrence and SPI.

$\bar{x}$ and $\bar{y}$ are the mean value of the variables of wildfire occurrence and SPI.

$n$ is the number of variables in two parameters.

In addition, the linear correlation $(r)$ in wildfire occurrence and SPI was investigated at the annual value, as well as statistical significance level ( $p$ ) chosen at the $90 \%$ in this research.

Three main groups have the six parameters. These six parameters are to influence a spatial distribution of the wildfire risk that was analysed by the following rank of importance; namely burnt area frequency, fire hotspot density, land cover type, fire danger level, Standardized Precipitation Index (SPI) and fire guard. In order to acquire data, the burnt area frequency, fire hotspot density and land cover type were derived by historical data of the Terra/Aqua MODIS satellite from 2000 to 2017. Also, they were obtained from fuel material; and fires break out easily and spread fast in the high frequented place. The fire danger level was created by the level of fire hazardous from Ministry of Nature, Environment and Tourism of Mongolia [MNET, 2017] and is based on the historical data of field-based such as botanic-ecological, forestvegetation and forest fires [Chuluunbaatar et al., 2014]. Moreover, SPI is identified the weather condition. Also, another most important parameter is a fire guard which is a position of fire extinguisher. It is mainly an influence on ignition and spread the wildfire. Table 1 shows the rank and weight of all six parameters.

Table 1 . The parameters of criteria in the study area

\begin{tabular}{|l|l|l|l|l|}
\hline No & $\begin{array}{l}\text { Parameter of } \\
\text { Criteria }\end{array}$ & $\begin{array}{l}\text { Straight } \\
\text { Rank }\end{array}$ & $\begin{array}{l}\text { Numerator } \\
(\mathbf{n}-\mathbf{r i}+\mathbf{1})\end{array}$ & $\begin{array}{l}\text { Normalized } \\
\text { Weights }\end{array}$ \\
\hline 1 & $\begin{array}{l}\text { Burnt area } \\
\text { frequency }\end{array}$ & 1 & 6 & 0.29 \\
\hline 2 & Fire hotspot density & 2 & 5 & 0.24 \\
\hline 3 & Land cover type & 3 & 4 & 0.19 \\
\hline 4 & Fire danger level & 4 & 3 & 0.14 \\
\hline 5 & SPI & 5 & 2 & 0.01 \\
\hline 6 & Fire guard & 6 & 1 & 0.05 \\
\hline Sum & 21 & 21 & 1 \\
\hline
\end{tabular}

As shown in Table 1, the straight rank of criteria includes the six parameters are classified by weighted value according to their effects to spread the wildfire. The weighted value of these parameters indicates that a low value of percentage is less influence to the risk. In contrary, a high value of percentage is significantly relevant in this study. To obtain effective and more accurate conclusions, the mathematical operations were analysed in GIS analysis.

\subsection{Data and data set}

We have carried out all data from Information and research institute of Meteorology, Hydrology and Environmental of Mongolia (IRIMHE, 2017). These data include the satellite

\begin{tabular}{|c|c|c|c|}
\hline Category & ID & Data List & Period \\
\hline \multirow{4}{*}{ GIS Vector } & 1 & Country boundary & \multirow{4}{*}{2006} \\
\hline & 2 & Province boundary & \\
\hline & 3 & Province center & \\
\hline & 4 & Soum boundary & \\
\hline \multirow{5}{*}{$\begin{array}{l}\text { GIS } \\
\text { Thematic } \\
\text { maps }\end{array}$} & 5 & Road network & 2008 \\
\hline & 6 & River, springs & 1992 \\
\hline & 7 & Lakes & 1992 \\
\hline & 8 & Tourist camps & 2008 \\
\hline & 9 & Fire Guard & 2017 \\
\hline \multirow{3}{*}{$\begin{array}{l}\text { Climatic } \\
\text { data }\end{array}$} & 10 & Air temperature & \multirow{3}{*}{$2000-2017$} \\
\hline & 11 & Rainfall & \\
\hline & 12 & SPI & \\
\hline \multirow{2}{*}{ Field data } & 13 & Fire danger level & 2014 \\
\hline & 14 & The amount of damage cost & 2012-2016 \\
\hline \multirow{3}{*}{$\begin{array}{l}\text { Satellite } \\
\text { data }\end{array}$} & 15 & MODIS hotspot & \multirow{2}{*}{ 2000-2017 } \\
\hline & 16 & MODIS Burnt area & \\
\hline & 17 & Land cover map & 2010 \\
\hline
\end{tabular}
imagery, map of the land cover thematic, field and climatic data. Table 2 shows the list of all datasets for this study.

Table 2. The list of used datasets

Furthermore, a risk map of the wildfire requires the integration of nature and environmental factors (fuel materials and biophysics and GIS thematic) and the anthropogenic factors (such as settlements, local-roads and croplands). The anthropogenic factors are mainly considered: the infrastructures such as settlements, tourist sites, roads and farmlands that are concerned as areas of high risk of the wildfire (Pew and Larsen, 2001) and some socioeconomic parameters are affiliated to the wildfire occurrence: cattle pasture, population and activity sectors, etc. (Roman-Cuesta et al., 2003). Climatic factors are mostly influenced to the wildfire activity which parameters include the air temperature and precipitation, etc. (Keeley and 
Syphard, 2016). Also, good agreement with dryness of climatic impacts somehow ignites the wildfires which the precipitation is a low. It means that there is a low amount of the water vapor in the air and the wildfires are occurred more (Bylow, 2012).

\section{RESULTS AND DISCUSSION}

The global and regional warming of climate is changed rapidly in the last decade due to the excessive precipitation and heavy rains will increase heat, dryness and wildfire resulting from the intensity of increasing year by year (Trenberth, 2005). Figure 3 shows that the statistical analyses of wildfire occurrences were performed over Mongolia in 2000-2017.

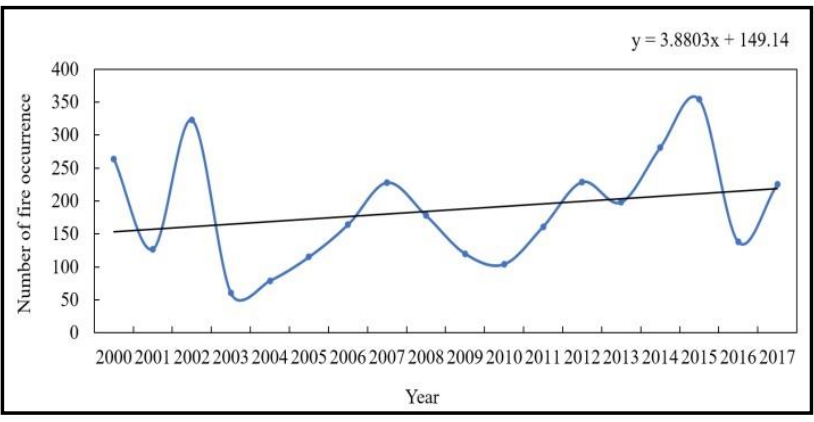

Figure 3. Number of the wildfire occurrence in Mongolia, 2000-2017

In Figure 3, a trend of the wildfire occurrence has been increased by 3-4 fires per year in the study area. Therefore, we have considered the statistical analysis in the study area which is the linear equation regression was used for relationship between wildfire occurrences and climatic parameter. A climatic parameter has been measured by meteorological data such as precipitation was estimated by SPI (Svoboda et al., 2012) from 2000 to 2017 in Mongolia. A comparison analysis of the wildfire occurrence and SPI illustrates in Figure 4. In order to compare between the wildfire occurrence and SPI, the annual value was merged from May to October for the year 2000 to 2017 in both variables.

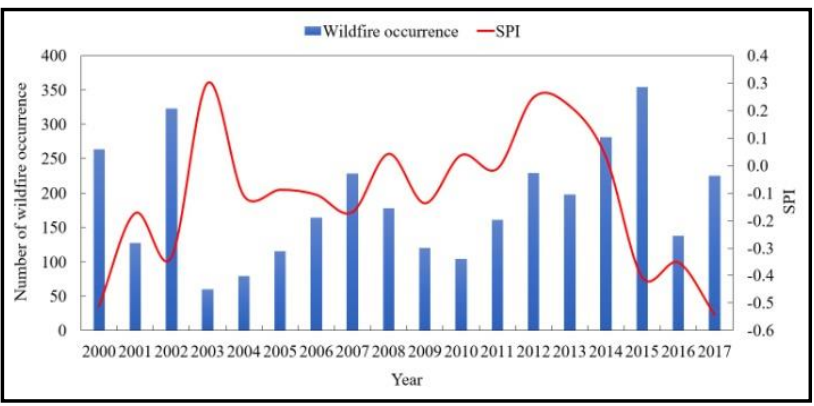

Figure 4. Temporal variation between wildfire occurrences and SPI, 2000-2017

Particularly, the attitude of the SPI was decreased in dry condition, whereas last 5 years of the SPI had been rapidly increased. In generally, these parameters between dryness and wild occurrence were well related with each other in the study period.

The correlation coefficient $(r)$ of the wildfire occurrence and SPI was negative 0.43 with a significance level of $p=0.13$. For example, the number of the wildfire occurrence was clearly appeared as dry condition of the years 2000-2002, 2005-2007, 2009, 2011 and 2015-2017 and there were between 100 and 400 .
Figure 5 shows the loss of ecological damage of the wildfire from 2012 to 2016 in Mongolia. The statistical data was obtained from Disaster Research Institute under National Emergency Agency of Mongolia (NEMA, 2016).

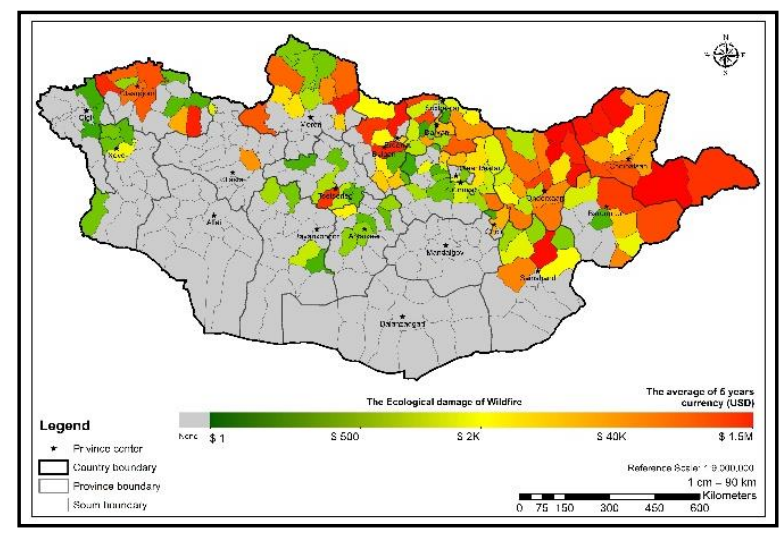

Figure 5. The loss of ecological damage of the wildfire in Mongolia by past years (2012-2016)

In Figure 5, the costs were only calculated for the ecological damage from the wildfire occurrences and it shows where high damaged area and how much cost of ecosystem effected during the study period.

In contrast, the wildfire map is illustrated a high value of the ecological damaged area from the eastern part to the northern part of Mongolia. For example, about 1.5 million USD dollars of the ecosystem was damaged area in the eastern part of the study area. Also, the northern part of area was more than 40 thousand USD dollars of the ecosystem. Furthermore, the northern part of area has mostly boreal forest and the eastern part of area is very important of wildlife habitats of the biodiversity. Particularly, this area locates the transition zone from the Eastern Mongolia steppe to the mountains and forest area of Manchuria.

Figure 6 presents a spatial distribution map of the wildlife risk is produced by the weighted overlay method of MCEA.

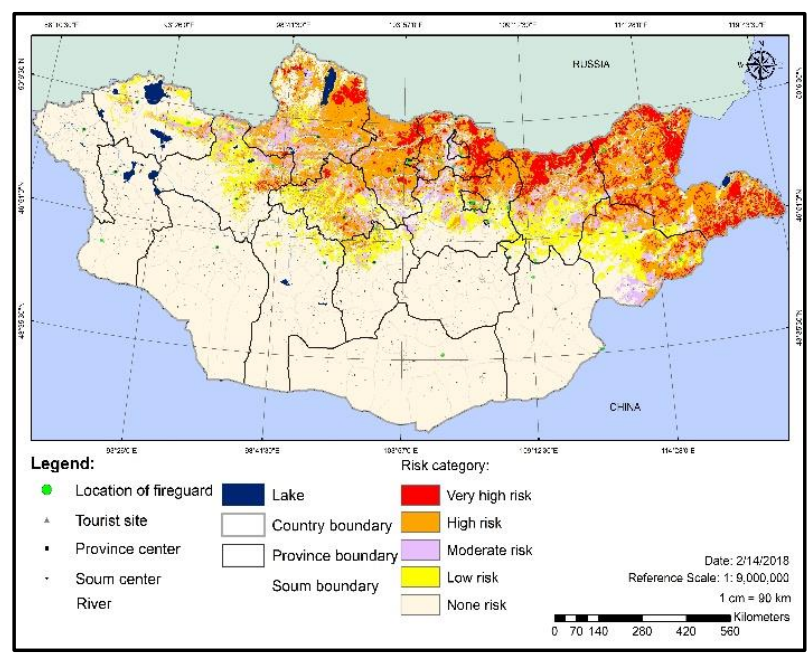

Figure 6. Spatial distribution map of the wildfire risk, 2017

In Figure 6, a spatial distribution map of the wildfire risk was classified into five categories of the wildfire risk; namely very high risk, high risk, moderate risk, low risk and none risk. A value of the wildfire risk in each category is expressed by percentage of the study area in 2017, as shown in Figure 7. 


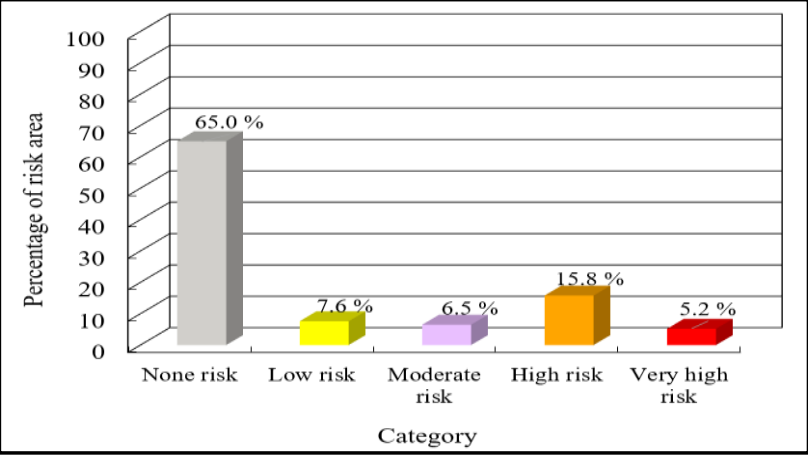

Figure 7. Spatial distribution of the wildfire with five categories by percentage, 2017

In Figure 7, a percentage of the study area was predicted by index of wildfire risk in each category as a proposed method. About 6 $8 \%$ of the study area was identified as categories of the moderate and low risk; but $5-16 \%$ of it estimated as very high and high risk. In remaining category, $65 \%$ of the study area was occupied as a large value in the none-risk so that it has semi-arid and desert zone.

\section{CONCLUSION}

This study performs that our proposed method was used to integrate the various factors with different spatial and temporal resolutions. These integrated factors include the social economic, environmental and climate, and wildfire damage. We used the method of Multi-Criteria Evaluation Analysis (MCEA); these factor components are provided to be useful in the identification of suitable areas for the wildfire risk within a GIS.

A risk map of the study area was classified into five categories and is based on spatial statistics adequately to assess a respective fire risk: very high risk, high risk, moderate risk, low and very low. Approximately half of third (37\%) of the study area was occupied a high probability within risk zones of the wildfire. In contrast, $5-16 \%$ of the study area identified as very high, high risk area, $6-8 \%$ of area was moderate and low risk, but $65 \%$ of it was observed as none risk in order to it has semi-arid and desert zone.

This investigation is the spatial and temporal resolutions of biophysical evaluation and provides the information at a regional level. Consequently, the wildfire risk map would be used to prevent the reduction fire risk, private section and farmers care to prepare a risk reduction for the national and local government agency.

Moreover, other more important specifically aspects are could be establish to more and more the firefighters in sub local level. Also, another most important condition due to improve such as legal framework of the wildfire firefighter, foundation funds, capacity building, technical equipment, technological level, fire prevention zone, a water point and complex early warning system to provide on mobile device these are based on wildfire risk map.

\section{ACKNOWLEDGEMENTS}

The researchers would like to thank the Earth Observing System Data and Information System (EOSDIS) is a key core capability in NASA's Earth Science Data Systems (ESDS) Program of United States of America (USA), eOsphere Limited (VxEos) of United Kingdom and National Remote Sensing Center (NRSC) of Mongolia for providing raw data and research work.

The authors are very thank to the Department of Forest Management of Ministry of Environment and Tourism and
Programme Management Unit of the United Nations collaborative initiative on Reducing Emissions from Deforestation and Forest Degradation (UN-REDD+) Mongolia National Programme and this program was partially conducted to help the financial support for our work.

\section{REFERENCES}

Alejandro, C. A., 2003. Delineation of suitable areas for crops using a Multi-Criteria Evaluation approach and land use/cover mapping a case study in Central Mexico. Elsevier Science. pp: 77, 117-136.

Altansukh, N., 2002. Plant genetic resources status and process of activities in Mongolia. Plant Genetic Resources in East Asia (IPGRI): Proceedings of the Meeting for the Regional Network for Conservation and Use of Plant Genetic Resources in East Asia, Ulaanbaatar, Mongolia. 13-16 August 2001, pp:27-34.

Badamsuren,D. Amarzaya, P. Sodnomragchaa, D. Mendelmaa, CH. Chimedtseren, P. (2016). Data book on Natural and human induced hazards in Mongolia 2014, 2015.

Batima, P.; Dagvadorj, D. (2000). Climate Change and Its Impacts in Mongolia; NAMHEM JEMR Publishing: Ulaanbaatar, Mongolia,

Bylow, D., 2012. Modeling Wildfire Hazard in the Western Hindu Kush Himalayas. pp:41-26.

Chhetri, S. K., \& Kayastha, P. (2015). Manifestation of an analytic hierarchy process (AHP) model on fire potential zonation mapping in Kathmandu Metropolitan City, Nepal. ISPRS International Journal of Geo-Information, 4(1), 400-417.

Cho, H. C., Lee, D. H., Ju, H., Park, H. C., Kim, H. Y., \& Kim, K. S. (2017). Fire Damage Assessment of Reinforced Concrete Structures Using Fuzzy Theory. Applied Sciences, 7(5), 518.

Chuluunbaatar, T., 1998. Fire in forest ecosystem of Mongolia. International Forest Fire News 19. pp:58-63

Chuluunbaatar, Ts., Tsedendash, G., Tuvshintogtokh, I., Manidari, D. 2014. Report of the danger level of Forest and steppe Fire, Ulaanbaatar, Mongolia.

CIA. World Factbook of the Work of a Nation, Central Intelligence Agency: https://www.cia.gov (12 February 2018)

Dong, X. U., Li-min, D., Guo-fan, S., Lei, T., \& Hui, W. (2005). Forest fire risk zone mapping from satellite images and GIS for Baihe Forestry Bureau, Jilin, China. Journal of forestry research, 16(3), 169-174.

Dorjsuren, M., Liou, Y. A., \& Cheng, C. H. (2016). Time series MODIS and in situ data analysis for Mongolia drought. Remote Sensing, 8(6), 509.

Elbegjargal, Nasanbat and Ochirkhuyag Lkhamjav., (2016). Wild fire risk map in the eastern steppe of Mongolia using spatial multi-criteria analysis. International Archives of the Photogrammetry, Remote Sensing \& Spatial Information Sciences, 1-9.

Erdenetuya, M., 2012. Fire occurrence and burning biomass statistics in Mongolia, The Proceedings of 33rd Asian Conference Remote Sensing. pp. 118-125. 
Garavand, S. and Yaralli, N., (2015). Assessment of Fire Risk in Central Zagros Forests in Chaharmahal Bakhtiari Province. International Journal of Review in Life Sciences 5(3). pp:538543.

Goldammer, J.G., 1999. Fire Situation in Mongolia. Freiburg Germany. International Forest Fire News (IFFN) 36. pp:5-8.

Huyen, D.Th.Th. and Tuan, V.A., (2008). Applying GIS and Multi Criteria Evaluation in forest fire risk zoning in SON LA PROVINCE, VIETNAM. International Symposium on Geoinformatics for Spatial Infrastructure Development in Earth and Allied Sciences. pp. 8

IRIMHE. 2017. Remote Sensing Product. Information and Research Institute of Meteorology, Hydrology and Environmental, Mongolia: http://irimhe.namem.gov.mn (22 January 2018).

Keeley, J. E., \& Syphard, A. D. (2016). Climate change and future fire regimes: examples from California. Geosciences, 6 (3), 37.

Khudulmur, S., Elbegjargal, N., Tsogtbaatar, J., Dash, D., Mandakh, N. 2014. Desertification Atlas of Mongolia; Institute of Geoecology, Mongolian Academy of Sciences; Swiss Agency for Development and Cooperation SDC; Environmental Information Center; Ulaanbaatar, Mongolia; pp.38-41.

Malczewski, J., 1999. GIS and Multicriteria Decision Analysis. John Wiley \& Sons. pp.177-190.

MNET. 2017. Ministry of Nature, Environment and Tourism of Mongolia. http://www.mne.mn (15 February 2018).

NAMEM. 2018. Archive and Database Division. from National Agency for Meteorology and Environmental Monitoring, Mongolia: http://namem.gov.mn (22 January 2018).

NEMA. 2016. Disaster Research Institute, National Emergency Agency of Mongolia: http://nema.gov.mn/ (10 November 2017).

NEMA., 2010. The News Bulleting of Disasters. Ulaanbaatar.

Ochirkhuyag, L., Fine, A., Didier, K. and Sanderson, E., (2008). The Eastern Steppe's Living Landscape, Mongolia. The Proceedings the ISPRS XXI Congress. pp.575-573.

Ochirsukh, B., 2011. GIS mapping for forest fire risk zone in Selenge, Mongolia. Spring Korea Geospatial Information Society Conference. pp.53-56.

Pew, K. L. and Larsen, C.P.S. (2001). GIS analysis of spatial and temporal patterns of human-caused wildfires in the temperate rain forest of Vancouver Island, Canada [J]. Forest Ecology and Management, 140: 1-18.

Román-Cuesta, R.M., Gracia, M. and Javier, R. (2003). Environmental and human factors influencing fire trends in ENSO and Non-ENSO years in tropical Mexico [J]. Ecological Applications, 13(4): 1177-1192.

Serjmyadag, D., Battulga, Z., Amarzaya, P., Sarantuya, R. (2010). The Bulleting of Disasters in Mongolia. pp:6-9
Svoboda, M., Hayes, M., \& Wood, D. (2012). Standardized precipitation index user guide. World Meteorological Organization Geneva, Switzerland.

Trenberth, K.E., 2005. The Impact of Climate Change and Variability on Heavy Precipitation, Floods, and Droughts. Encyclopedia of hydrological sciences. 1-2.

Yao, J., \& Zhang, X. (2016). Spatial-Temporal Dynamics of Urban Fire Incidents: A Case Study of Nanjing, China. ISPRSInternational Archives of the Photogrammetry, Remote Sensing and Spatial Information Sciences, 63-69. 